\title{
Carbon Back Sputter Modeling for Hall Thruster Testing
}

\author{
James H. Gilland ${ }^{1}$, George J. Williams ${ }^{2}$, Jonathan M. Burt ${ }^{3}$ \\ Ohio Aerospace Institute, Brook Park, Ohio, 44142 \\ John T. Yim ${ }^{4}$ \\ NASA Glenn Research Center, Cleveland, Ohio, 44135
}

\begin{abstract}
Lifetime requirements for electric propulsion devices, including Hall Effect thrusters, are continually increasing, driven in part by NASA's inclusion of this technology in it's exploration architecture. NASA will demonstrate high-power electric propulsion system on the Solar Electric Propulsion Technology Demonstration Mission (SEP TDM). The Asteroid Redirect Robotic mission is one candidate SEP TDM, which is projected to require tens of thousands of thruster life. As thruster life is increased, for example through the use of improved magnetic field designs, the relative influence of facility effects increases. One such effect is the sputtering and redeposition, or back sputter, of facility materials by the high energy thruster plumes. In support of wear testing for the Hall Effect Rocket with Magnetic Shielding (HERMeS) project, the back sputter from a Hall effect thruster plume has been modeled for the NASA Glenn Research Center's Vacuum Facility 5. The predicted wear at a near-worst case condition of $600 \mathrm{~V}, 12.5 \mathrm{~kW}$ was found to be on the order of $1 \mu \mathrm{m} / \mathrm{kh}$ in a fully carbon-lined chamber. A more detailed numerical monte carlo code was also modified to estimate back sputter for a detailed facility and pumping configuration. This code demonstrated similar back sputter rate distributions, but is not yet accurately modeling the magnitudes. The modeling has been benchmarked to recent HERMeS wear testing, using multiple microbalance measurements. These recent measurements have yielded values on the order of $1.5-2 \mu \mathrm{m} / \mathrm{kh}$ at $600 \mathrm{~V}$ and $12.5 \mathrm{~kW}$.
\end{abstract}

\section{Nomenclature}

$\mathrm{ARM}=$ Asteroid Redirect Mission

ARRM $=$ Asteroid Redirect Robotic Mission

DSMC $=$ Direct Simulation Monte Carlo

$\mathrm{E}_{\mathrm{i}} \quad=$ Incident particle energy, $\mathrm{eV}$

GRC $=$ Glenn Research Center

HAP $=$ Hypersonic Aerothermodynamics Particle

HERMeS $=$ Hall Effect Rocket with Magnetic Shielding

JPL $=$ Jet Propulsion Laboratory

$\mathrm{j}=$ Current density distribution, $\mathrm{A} / \mathrm{m}^{2}$

$\mathrm{kh}=$ Kilohour

$\mathrm{L}=$ Vacuum chamber length, $\mathrm{m}$

MPD $=$ Magnetoplasmadynamic

$\mathrm{QCM}=$ Quartz Crystal Microbalance

$\mathrm{R}=$ Vacuum chamber radius, $\mathrm{m}$

$\mathrm{TDM}=$ Technology Demonstration Mission

TDU $=$ Technology Demonstration Unit

\footnotetext{
${ }^{1}$ Research Team Manager, Ohio Aerospace Institute, Associate Fellow AIAA

${ }^{2}$ Senior Scientist, Ohio Aerospace Institute, Associate Fellow AIAA

${ }^{3}$ Scientist, Ohio Aerospace Institute, Member AIAA

${ }^{4}$ Research Engineer, NASA Glenn Research Center, Member AIAA
} 


$\begin{array}{ll}\text { VF } & =\text { View Factor relation } \\ \text { VHS } & =\text { Variable Hard Sphere } \\ \text { VF-5 } & =\text { Vacuum Facility } 5 \text { at NASA Glenn Research Center } \\ Y_{\text {tot }} & =\text { Total Sputter Yield } \\ Y_{0} & =\text { Normal Incidence Sputter Yield } \\ \alpha & =\text { Sputtered particle angle to surface normal } \\ \beta & =\text { Particle incident angle to the surface normal } \\ \gamma & =\text { Sputtered particle azimuthal angle } \\ \theta & =\text { Azimuthal angle about vacuum chamber axis }\end{array}$

\section{Introduction}

$\mathrm{T}$ o demonstrate high-power, high-specific-impulse performance for the Asteroid Redirect Robotic Mission (ARRM), both in terms of desired mission capability and required lifetime, a joint NASA Glenn Research Center (GRC) and Jet Propulsion Laboratory team have developed the $12.5 \mathrm{~kW}$ Hall Effect Rocket with Magnetic Shielding (HERMeS) ${ }^{1}$. To demonstrate that HERMeS meets the desired specification and to reduce several key risks associated with the thruster, two Technology Demonstration Units (TDUs) were fabricated and tested. The design of HERMeS incorporates technologies developed by NASA over nearly two decades, and is enabled through the use of magnetic shielding to effectively eliminate discharge chamber erosion ${ }^{2,3,4,5}$. The result is a significant increase in the operational lifetime of state-of-the-art for Hall thrusters, with HERMeS being designed to operate at $3000 \mathrm{~s}$ specific impulse with a lifetime exceeding $50 \mathrm{kh}$. The methodology used to design HERMeS emphasized the use of thermal, structural, and physics-based plasma modeling that were used in nearly every aspect of the thruster design to achieve its design goals. ${ }^{4,6,7}$ The design of HERMeS resulting from this approach uses an integrated magnetic and thermal design, pole piece covers, a graphite cathode keeper, an internally mounted cathode, and a downstream-plenum gas distributor.

Electric propulsion systems face testing challenges for development and qualification due to the need to accurately simulate the space environment in which they will operate and the operating lifetimes over which they must operate to satisfy mission requirements. ${ }^{8,9,10,11}$ The impact of these requirements on vacuum facility requirements is multifold, in terms of being able to simultaneously test both performance and life. Performance can be affected through the interaction of thruster plumes with both the background gas and the facility itself ${ }^{12}$. In the extended operation of thrusters for lifetime evaluation, the facility can also affect the measurements through the sputtering, and ultimate deposition, of sputtered material from the facility surfaces on the thruster, as well as from the thruster itself. This effect has been observed in ion thruster testing (NSTAR and NEXT), where carbon films from the facility walls were observed forming in the lower current density, outer regions of the grids. ${ }^{13}$ The effect of facility backpressure on thruster performance has been observed in multiple devices over the decades of thruster development, including ion thrusters, MPD thrusters ${ }^{14}$, and Hall thrusters. A great deal of effort has been expended on developing facilities that could maintain backpressure levels below the empirically identified threshold for facility effects on thruster operation or performance. Entrained gas, recycled gas, increased ion-neutral collisions, all have been found to affect thruster behavior relative to space conditions. Values less than $10^{-5}$ torr have generally been considered to provide accurate measurements of HET properties ${ }^{15}$; however, operation at higher powers have shown changes in performance even at these values?

Relating the measured erosion and deposition rates in the vacuum facility to that experienced in space is an ongoing challenge, one that must now be addressed for Hall thruster operation, as well. Hall thrusters were originally used for relatively short duration, low-power Earth orbital missions, which did not require extended testing, or show signs of deposition. Recently, Hall thruster missions requiring increased life and increased power have come to the fore; also, new approaches for reducing thruster erosion have been identified. Combined, these requirements and capabilities now introduce the need to consider facility deposition effects for Hall thrusters as well. Specifically, the NASA Asteroid Redirect Robotic Mission (ARRM) ${ }^{16}$ has baselined a higher power (12.5 $\mathrm{kW}$ ), longer lived thruster, utilizing the recently proposed concept of Magnetic Shielding, which promises to virtually eliminate insulator erosion ${ }^{17}$. In order to fully predict and characterize the lifetime of such high-power Hall thrusters, relevant models incorporating facility design and thruster operation parameters are needed. Two approaches have been used to predict facility back sputter rates for a high power Hall thruster operated in the NASA Glenn Research Vacuum Facility 5 (VF-5): an analytic ray tracing method previously used for ion thruster back sputter calculations, and a Direct Simulation Monte Carlo (DSMC) numerical model incorporating the thruster plume and a detailed facility geometry of facility walls and pumping surfaces. The modeling effort is supported during the HERMeS program by ongoing measurements of back sputtered material at the thruster plane, both in real 
time using multiple Quartz Crystal Microbalances (QCMs), and in a time integrated manner through the use of passive witness surfaces located throughout the chamber, which can be removed and assessed after extended operation. Both the modeling and the measurements are primarily focused on particle back fluxes to the thruster plane.

\section{Facility Back Sputter Models}

The sputtering of material from facility walls depends on the facility geometry and wall composition, and the thruster plume energy, current, and divergence. The wall material defines the total amount of particles generated per incident particle impact. Facility geometry and thruster divergence dictate the incident angle, and therefor sputter yield, of Xenon atoms on the facility walls. Thruster plume currents and energies define the incident particle flux and total sputter yield of the facility material. Finally, the angular distribution of sputtered particles will determine the amounts of material that actually reach the thruster plane to deposit. For both models considered, the fundamental sputtering yield calculated at the surface is essentially the same:

$$
Y\left(E_{i}, \beta, \alpha, \gamma\right)=Y_{0}\left(E_{i}\right) f(\beta) g(\alpha, \gamma)
$$

The simplest relationship has $\mathrm{f}(\beta)=\operatorname{Sec}(\beta)$, and $\mathrm{g}(\alpha, \gamma)=\operatorname{Cos}(\alpha) / \pi$; however, for these analyses, a more empirical relationship was used for the $\beta$ dependence. $\mathrm{Y}_{0}\left(\mathrm{E}_{\mathrm{i}}\right)$ is the sputter yield for normal incidence, which is dependent on material properties. Carbon (graphite) has a low sputtering yield compared to most steel materials, and was assumed for all modeling. VF-5 was lined with carbon during the development and implementation of the models, and was modeled as fully graphite lined.

Carbon sputtering yields, both normal and as a function of incident angle, were taken from empirical measurements by Kolasinski et al. ${ }^{18}$ The normal yield is shown in Figure 1, and was fit with a power curve:

$$
Y_{0}=4.123 \times 10^{-5} E_{i}^{1.388}
$$

The incidence angle dependence data is also from Kolasinski (Figure 2), and was fitted to a power curve to the secant of the angle :

$$
f(\beta)=\frac{e^{-1.0556(-1+\operatorname{Sec}(\beta))}}{\operatorname{Cos}(\beta)^{3.427}}
$$

A more detailed model, the modified Zhang model, incorporates all of the dependencies described above ${ }^{19}$. However, it incorporates a empirical energy dependence based on a characteristic parameter $\mathrm{E}^{*}$, which is not constant over the range of energies considered in these analyses, so this form of sputter yield calculation was not considered further.

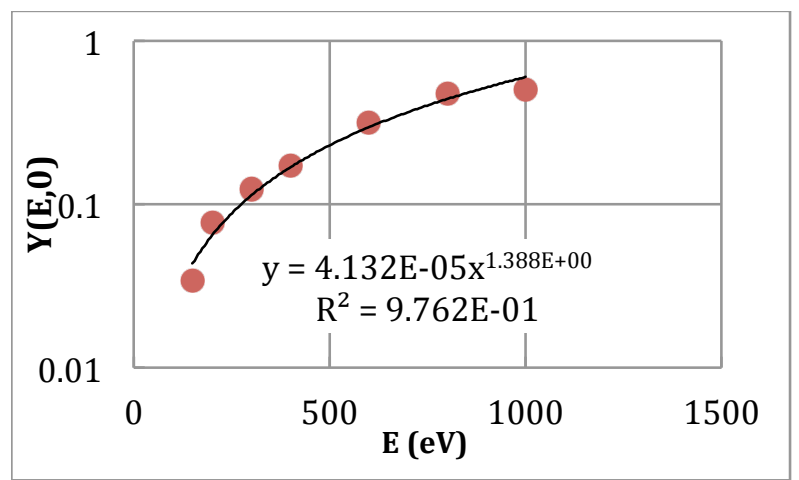

Figure 1. C sputter yield data from Xe bombardment.

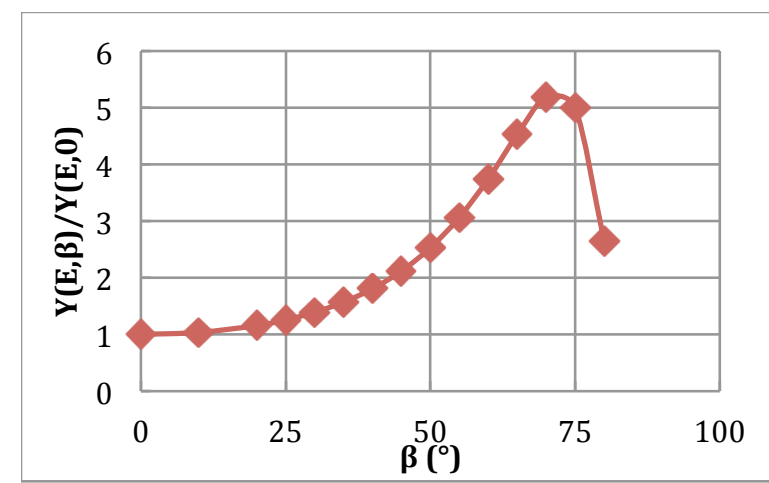

Figure 2. Incidence angle dependence for $\mathrm{C}$ sputtering by Xe (Equation 3).

3

American Institute of Aeronautics and Astronautics 


\section{A. Analytic Sputter Model}

As an initial approach for calculating back sputtered material, a method previously developed and applied to gridded ion thruster life testing was adapted to Hall thruster testing. The challenge in adapting the previous model to Hall thrusters is the more divergent and complex plume relative to an ion thruster beam. The original study used an analytic formula to model the ion beam, and a constant beam energy ${ }^{20}$. This yielded realistic results for assessing ion thrusters ${ }^{21}$, but fitting the original model to a Hall thruster plume loses the plume current distribution and energy distribution details inherent to a Hall thruster.

In order to incorporate this detail, the model assumptions (line of sight, cylindrical geometry, thruster as a point source) were maintained; however, the analytic current distribution was discarded, and empirical data from actual thruster operation is used as a spline fit. This data includes both current and energy distributions, to accommodate side lobes that have been observed in Hall thruster data. The thruster data used were the Hall Effect Rocket with Magnetic Shielding (HERMeS), a high power (up to $12.5 \mathrm{kWe}$ ), long life thruster currently in development. The plume profile was calculated using a new plume model developed by JPL for the HERMeS program ${ }^{22}$. The plume code is benchmarked to experimental probe measurements of the HERMeS thruster. From this modeling, data for particle density, velocity, and energy over $180^{\circ}$ at a fixed radius of $1 \mathrm{~m}$ are used as the input. The plume is then assumed to propagate by line of sight to the chamber walls; the expansion is taken as from a point source, with total flux maintained. Representative plumes are shown in Figure 3, in relation to dimensions corresponding to those of VF-5. This is the effective number flux used for the sputter calculations, but the particle energies are not constant at each angle, as shown in the corresponding energy maps in Figure 4.

At the walls, the sputter yield at each point is calculated using Equations 1 and 2, and a Cosine distribution of the sputtered particles is assumed. The analysis assumes a simple, axisymmetric cylindrical vacuum chamber, fully lined with graphite. The total particle back sputter to the thruster plane is then calculated using view factors, and integrated over the vacuum chamber walls. Because the flux and energy have more complex profiles than the analytic fit used for ion thruster modeling, the Hall thruster analysis requires numerical integration of the sputtering equations. This is done using Mathematica.

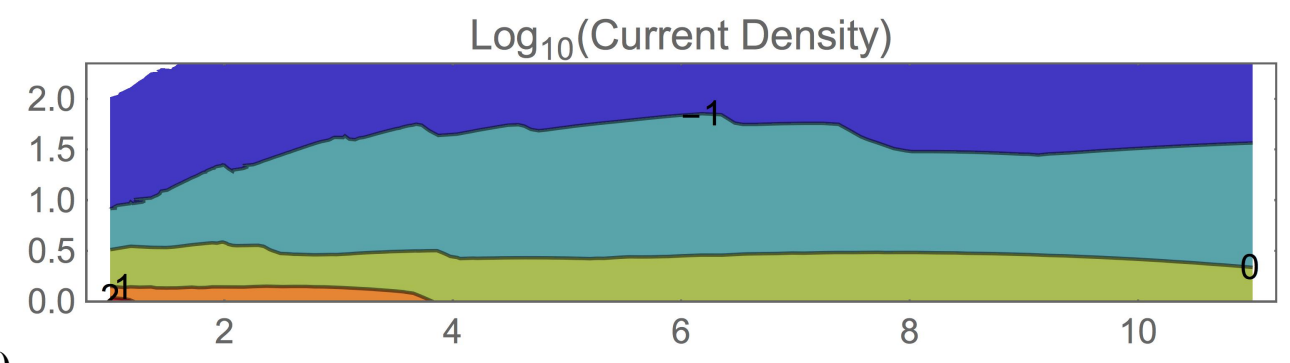

a.)

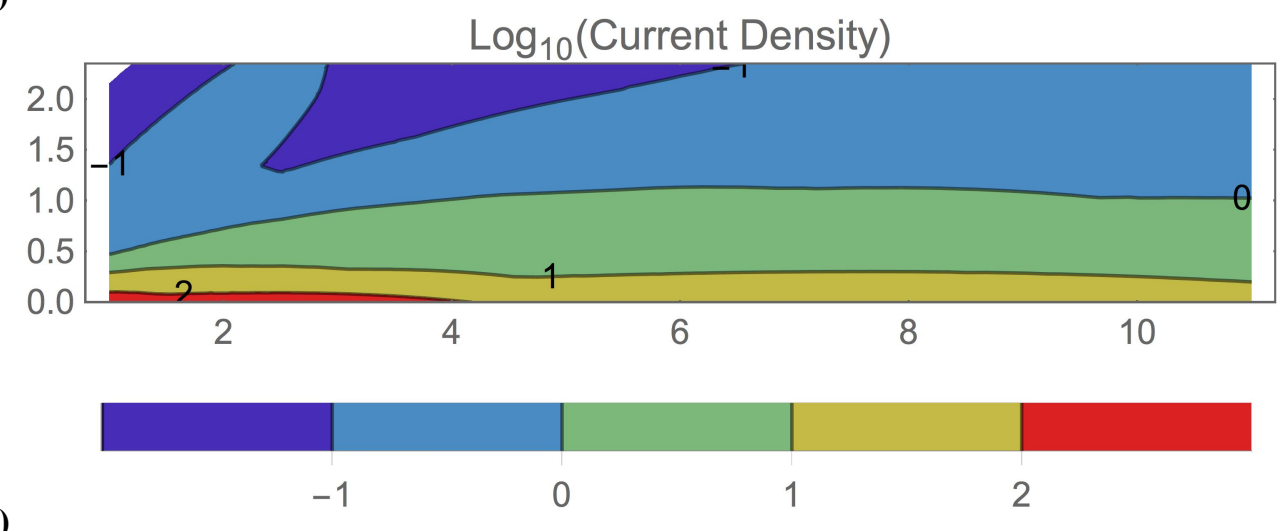

Figure 3. Fitted plume current density contours for analytic back sputter modeling: a.) $300 \mathrm{~V} 9.4 \mathrm{~kW}, \mathrm{~b}$.) $600 \mathrm{~V}$, 12.5 kW. 

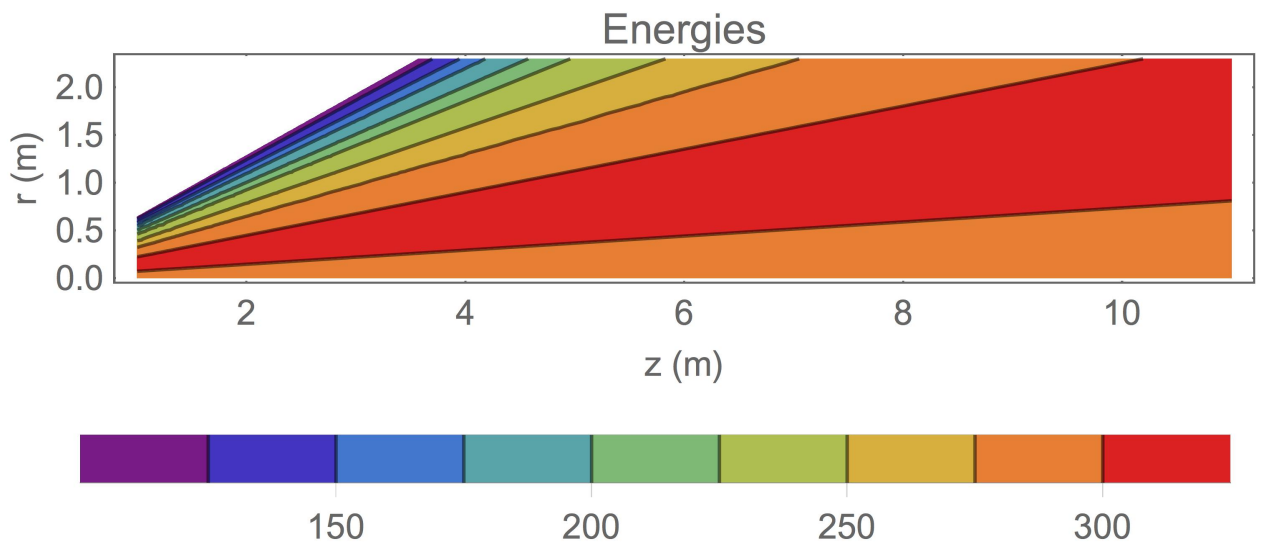

a.)
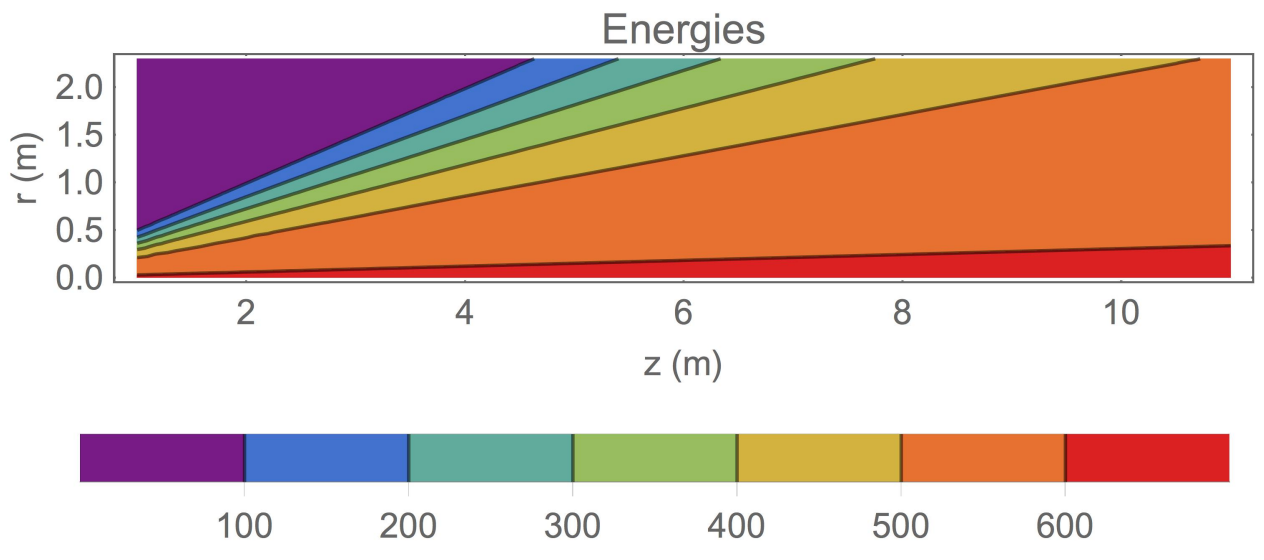

b.)

Figure 4. Fitted energy contours for analytic back sputter modeling: a.) $300 \mathrm{~V} 9.4$ kW, b.) $600 \mathrm{~V}, 12.5 \mathrm{~kW}$.

\section{B. DSMC Modeling}

The second approach utilizes a DSMC code, the Hypersonic Aerothermodynamics Particle (HAP) code ${ }^{23}$. The HAP code is a three dimensional DSMC which tracks a large group of simulated particles through space, allowing for probabilistic interactions through collisions to simulate a flow. HAP is a general Cartesian implementation of DSMC, with dynamic grid adaptation and options to import externally defined surface geometries or to automatically generate triangulated surfaces based on analytical geometry definitions. Interactions are modeled with energy dependent cross sections using the Variable Hard Sphere (VHS) approach. Species reference diameters are: Xenon: $5.74 \AA$, Carbon: $3.23 \AA$, with an energy variation term $(\omega)$ of 0.35 . The energy scaling of the VHS model was based on a reference temperature of $273 \mathrm{~K}$. Multiple particle species particles can be tracked; xenon and carbon were modeled in this work Xenon is input to the domain on a spherical surface, with particle densities and velocities derived from thruster probe data. Carbon is created through sputter interactions at surfaces. Surface interactions were modeled with a sticking coefficient between 0 and 1 , with xenon partially sticking to pump surfaces and carbon sticking to all surfaces.

The HAP code was implemented to model the generation and flow of sputtered carbon in the exact facility used for testing, including pumping surfaces. This code was used because it had already been configured to model the facility of interest, including pumping surfaces ${ }^{24}$. A later addition to the VF-5 geometry in HAP was a beam dump at the end of VF-5, consisting of a series of graphite panels angled at $10^{\circ}-30^{\circ}$ to the vertical, intended to reduce back sputter. The beam dump had been planned for installation prior to the modeling, and was included to make the prediction as close to reality as possible. The nominal VF-5 geometry is show in Figure 5, with pumping surfaces and the plume inflow boundary shown. The chamber and pump configuration is horizontally symmetric, so only half of the chamber is modeled. The same plume profile data were used for both the analytic and HAP inflow input. 


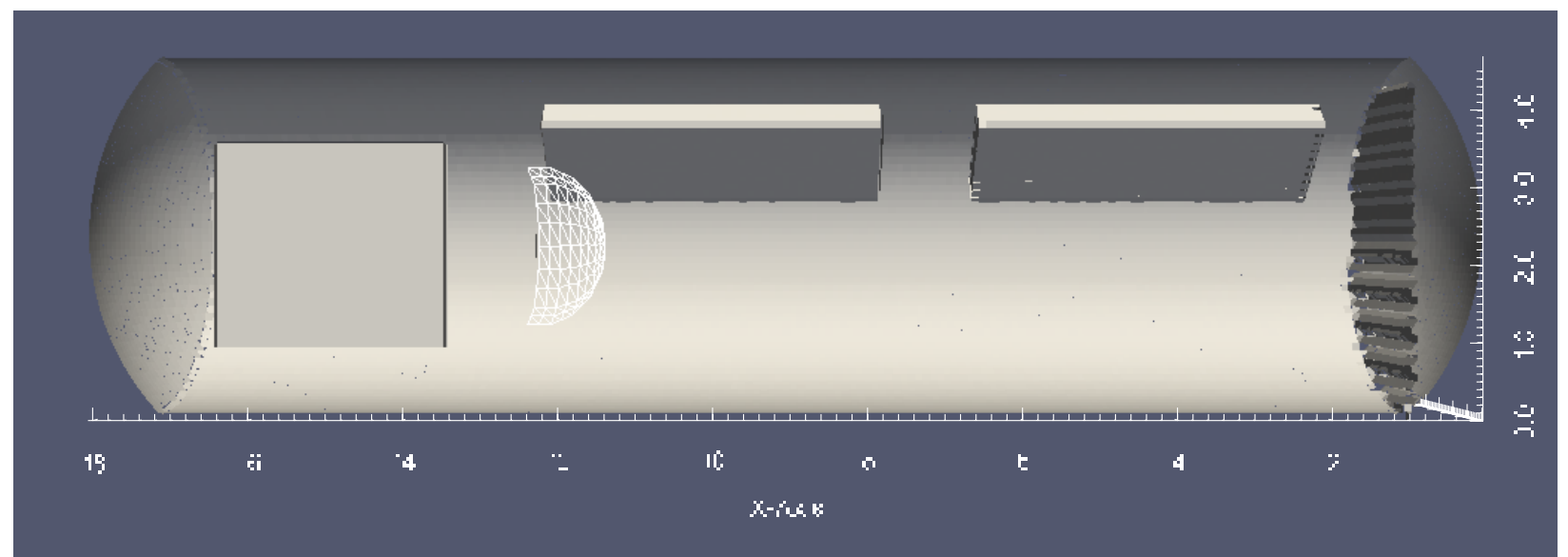

Figure 5. Simulated VF-5 regime, with pumping surfaces and beam dump. Inflow boundary for thruster plume is shown as a wireframe quarter sphere.

\section{Experimental Measurements}

The HERMeS thruster is currently undergoing a 2000 hour wear test, one part of which is the prediction, and measurement, of facility back sputter rates in the carbonlined VF-5 facility. ${ }^{25}$ An experimental plan to assess the carbon back sputter deposition in the HERMeS wear test was designed and implemented to complement and benchmark modeling. Three Inficon Quartz Crystal Microbalances (QCMs) have been installed at the thruster plane in VF-5. These QCM's are located approximately 1 $\mathrm{m}$ from the thruster axis; two on either side of the thruster below the thruster plane, and one elevated closer to the thruster axis (Figure 6). At this writing, the thruster has been operated over 400 hours, primarily at the wear test condition of $600 \mathrm{~V}, 12.5 \mathrm{~kW}$. At least one of the QCM's has been operating at all times during testing, and all three have been used simultaneously for much of the testing. This has allowed measurement of uniformity and rate during testing. In addition to the continuous measurement of depostion with the QCM's, passive witness coupons of Boron Nitride and Tantalum have been located throughout the vacuum facility to offer an integrated check on facility

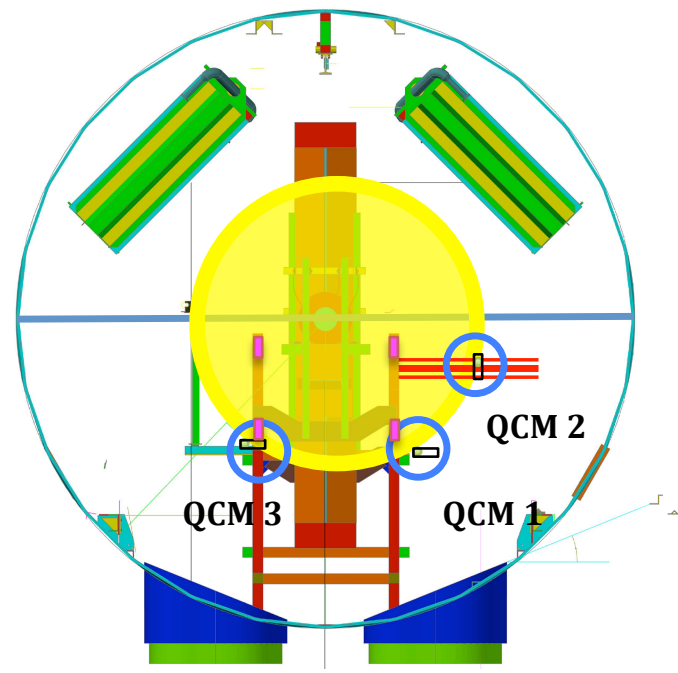

Figure 6. Arrangement of QCM's for monitoring facility back sputter deposition during HERMeS wear test. deposition over the course of the test. These require extended exposure (hundreds to thousands of hours) in order to fully indentify a deposition thickness and composition.

QCM output is scaled to carbon deposition; the reported deposition rates are in micrometers/thousands of hours, or $\mu \mathrm{m} / \mathrm{kh}$. The pure graphite density of $2.267 \mathrm{~kg} / \mathrm{m}^{3}$ is assumed for the deposition thickness; amorphous carbon deposition would result in lower densities. The instantaneous deposition rates measured by the instrumentation are near the limits of resolution of the QCMs; accurate determination of deposition rates requires data taken at a single operating condition over a day or more to most accurately calculate deposition rates. The QCM's can resolve thickness changes to $10^{-4} \mu \mathrm{m}$. The rate is resolvable over periods of ten or more minutes to within $0.36 \mu \mathrm{m} / \mathrm{kh}$ based on the observed times for the QCM thickness to increment.

\section{Results}

\section{A. Analytic Model}

Two HERMeS cases were analyzed using the analytic model: (1) $300 \mathrm{~V}, 9.4 \mathrm{~kW}$ and (2) $600 \mathrm{~V}, 12.5 \mathrm{~kW}$. These were chosen to span a range of plume divergence, energy, and currents. The model was used to examine 
several aspects of the back sputter question: the uniformity of the sputtered material across the thruster plane, the relative contributions of sputtering from the walls and end cap, and the direction of the sputtered material as it reaches the thruster. The two cases used two different plume models, both in current and energy profile, based on experimental data and plume modeling benchmarked to that data.

The radial distribution of carbon deposition rate in the thruster plane for both cases is shown in Figure 7. As would be expected, the lower voltage and power operation results in lower back sputter. The back sputter rates are uniform to within $10 \%$ across the chamber radius; on the scale of the thruster diameter, it is essentially uniform. The predicted back sputter rates to the thruster center line are $0.9 \mu \mathrm{m} / \mathrm{kh}$ at $300 \mathrm{~V}$ and $1.1 \mu \mathrm{m} / \mathrm{kh}$ at $600 \mathrm{~V}$. Of this total back sputter, the relative distribution from the chamber sides and end cap for each case are shown in Figure 8. Back sputter from the side walls dominates for the $300 \mathrm{~V}$ case, due to the greater divergence at lower voltages. The $600 \mathrm{~V}$ case, with decreased divergence, shows a nearly equal contribution from the sides and end cap, with wall sputtering dominating at radii beyond $1.3 \mathrm{~m}$. This calculation assumed a flat end wall; attempts at approximating a conical "beam dump" at the end of the chamber resulted in a slight (10\%) decrease in the overall back sputter rate.

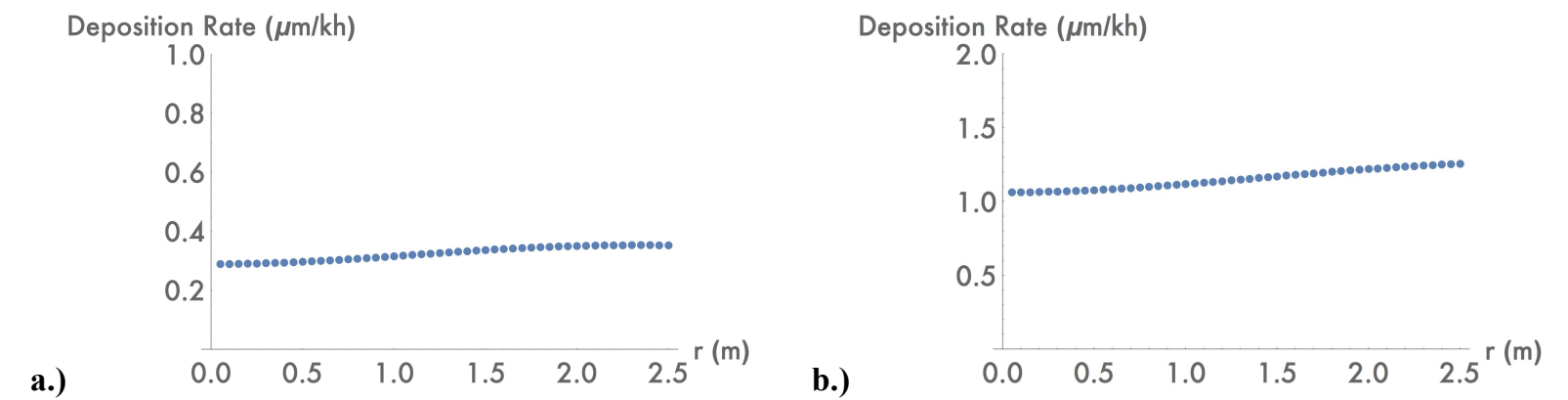

Figure 7. Carbon sputter deposition across VF-5 chamber radius at thruster plane for a.) $300 \mathrm{~V}, 9.4 \mathrm{~kW}$ and b.) $600 \mathrm{~V}$, $12.5 \mathrm{~kW}$. Thruster is located at the center.
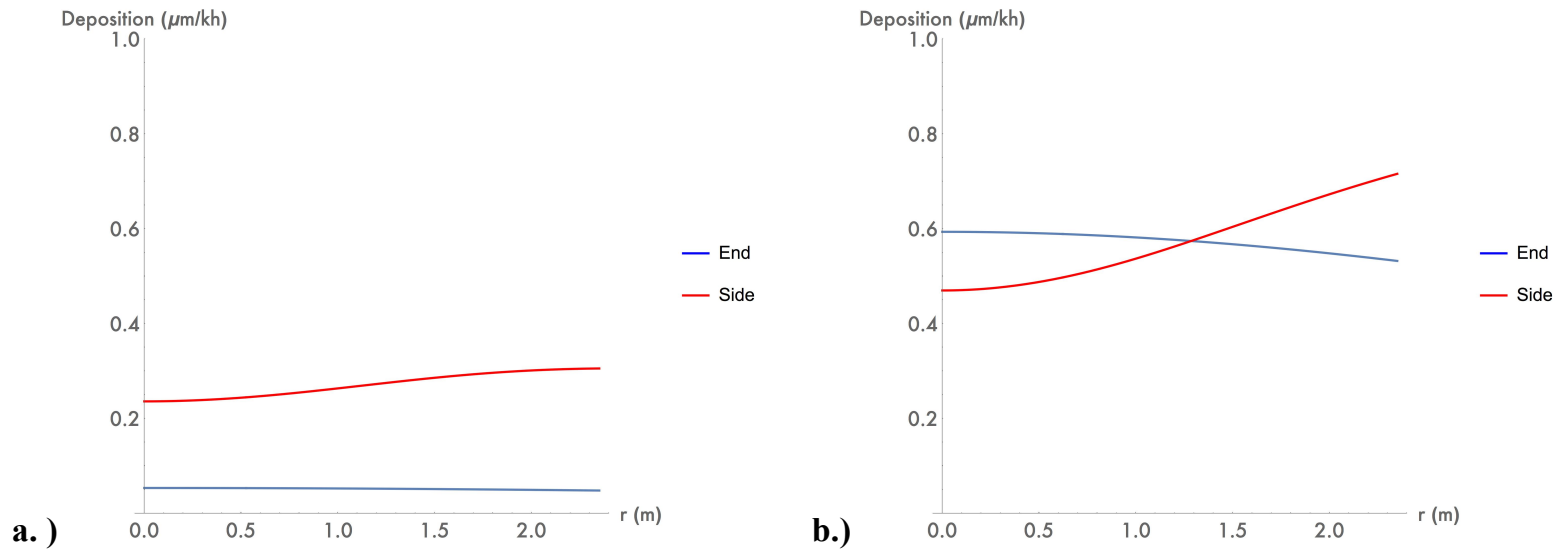

Figure 8. Relative carbon fluxes from walls and end cap to the thruster plane for a.) $300 \mathrm{~V}, 9.4 \mathrm{~kW}$ and b.) $600 \mathrm{~V}, 12.5$ $\mathrm{kW}$.

The location on the chamber walls where the most carbon returns to the thruster plane is a function of incident and sputtered angles, and can be calculated in the analytic model. The carbon arrival rate at the thruster from the walls and end cap varies with the axial location on the chamber wall, and the radial location on the end cap. These values were calculated along the wall length and across the end cap and are shown in Figure 9. These values are a differential contribution from each axial (wall) or radial (end cap) location to a fixed radius at the thruster plane, not the total contribution as shown in Figure 8. The calculation includes the incident current, the sputter differential yield, and the view factors for transport of sputtered materials from the surface back to the thruster. This is expressed symbolically in Equation 4. In this model, $\mathrm{R}$ is the radius of the chamber, $\mathrm{L}$ is the chamber length, $\theta$ is 
the azimuthal angle around the chamber axis, and VF represents the view factor between the sputter location and a point on the thruster plane. The wall flux contribution is calculated for

differential cylindrical sections along the chamber length. The radial flux is calculated for elemental annuli on the end cap.

$$
\begin{aligned}
& \text { Wall Flux }=\int_{0}^{L} \int_{0}^{2 \pi} j(R, z) Y\left[E_{i}(R, z), \beta, \alpha, \gamma\right] V F(R, z, \alpha, \gamma) R d \theta d z \\
& \text { End Cap Flux }=\sum_{i} \int_{r_{i}}^{r_{i+1}} \int_{0}^{2 \pi} j(r, L) Y\left[E_{i}(r, L), \beta, \alpha, \gamma\right] V F(r, L, \alpha, \gamma) r d \theta d r
\end{aligned}
$$

The end cap differential contribution includes the area from which the carbon is being sputtered. Although the peak current is at the center of the end cap, the area over which the greatest total sputtering is small at the center, resulting in a lower value from the center than from farther out on the end cap. In Figure 8, the relative effects of divergence can be seen in the closer axial location of the sputter contribution, and the wider end cap contribution, for the more divergent $300 \mathrm{~V}$ plume. The greatest contribution from the walls occurs at $2-6 \mathrm{~m}$ for the $300 \mathrm{~V}$ case, and from $4-8 \mathrm{~m}$ in the $600 \mathrm{~m}$ case. This variation indicates the broader plume at $300 \mathrm{~V}$, with more high energy particles intercepting the wall close to the thruster. Contributions to thruster back sputter from closer axial positions may also be diminished due to the reduced sputter yields at the resultant angles between the wall and the thruster.
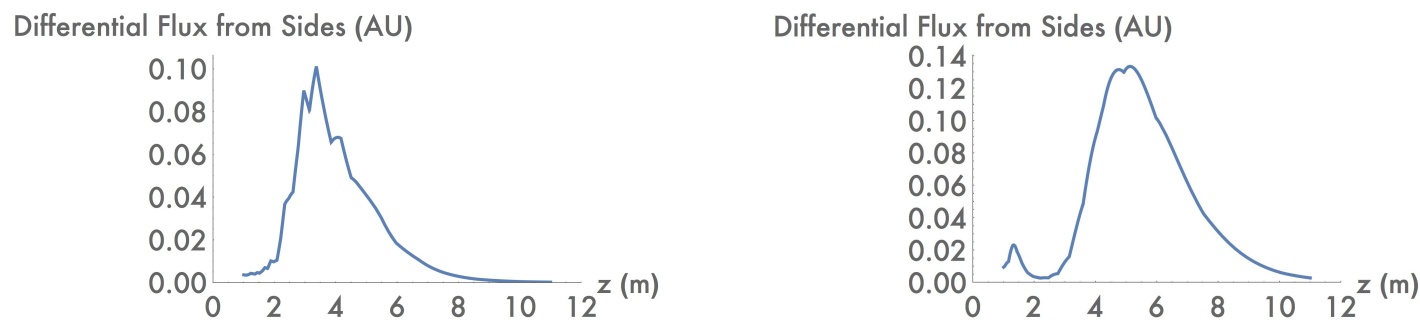

Differential Flux from End(AU)
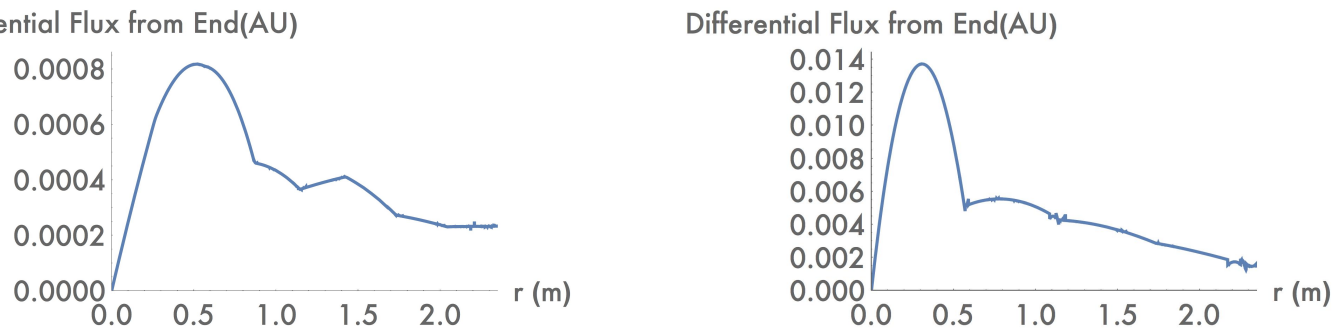

a.)

b.)

Figure 9. Location of the highest contribution of sputtered material across the thruster plane for a.) $300 \mathrm{~V}, 9.4 \mathrm{~kW}$ and b.) $600 \mathrm{~V}, 12.5 \mathrm{~kW}$ plumes.

The angle of carbon flux at the thruster plane is also of interest for determining possible carbon deposition on the discharge channel. Because of the line of sight assumptions inherent in the model, this can also be calculated at the location of the thruster channel in the chamber. This can be shown as a polar plot of the amount of flux as a function of angle coming into the channel. The directional flux of carbon into the center of a thruster discharge channel for both cases is shown in blue in Figure 10. The red rectangles show the chamber walls; the actual dimensions of the chamber have been omitted. The magnitude (length) of the distribution is normalized for each case, to indicate the relative location of carbon deposition in the channel. The lower voltage case (a) shows a broader deposition pattern, with more radial flux to the walls due to the increased contribution of side sputtered carbon for the more divergent $300 \mathrm{~V}$ plume. The channel deposition for the more collimated $600 \mathrm{~V}$ beam indicates a greater contribution from the farthest side walls and end, with less flux to the side walls. 


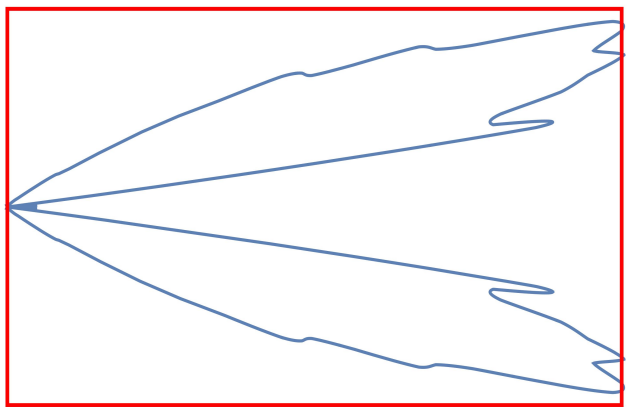

a.)

Figure 10. Relative direction of sputtered particles in a notional thruster channel for a.) $300 \mathrm{~V}$ and b.) $600 \mathrm{~V}$. Dimensions are not to scale.

\section{DSMC Modeling}

HAP modeling was done for similar HERMeS operating conditions to those analyzed. The code offers the opportunity to model sputtering of the actual pumping surfaces, including the beam dump being used in the current HERMeS wear test. Equations 2-3 were used to define the sputter yield at all surfaces. HAP calculates the number of carbon particles produced by a surface collision, and probablistically assigns sputter directions and amounts according to a diffuse (cosine) distribution. The program then follows the carbon particles deterministically, allowing for sticking to other surfaces and collisions with other particles. The carbon flux backward in the axial direction that reaches the thruster plane is the back sputter of concern to testing. Calculations within and behind the inflow boundary (a quarter sphere of one meter radius, centered on the thruster location $10 \mathrm{~cm}$ belown the central axis, at $12.4 \mathrm{~m}$ from the far end of the chamber, as shown in Figure 5) are not considered accurate due to the interaction of the input plume and the calculated flows of carbon and xenon. As a result, back sputter is calculated at an axial position of $11.5 \mathrm{~m}, 0.1 \mathrm{~m}$ downstream of the inflow boundary. The axial flux of carbon across this plane is used to calculate deposition rates.

At this writing, HAP has predicted a higher magnitude of back sputter than the analytic model; predicted back sputter layer growths are on the order of 25 times that predicted by the analytic model, and on the order of five times higher than that observed in VF-5 prior to lining it with carbon. The reason for this difference is still being examined. The distribution and source of the back sputter in an accurate representation of the vacuum chamber

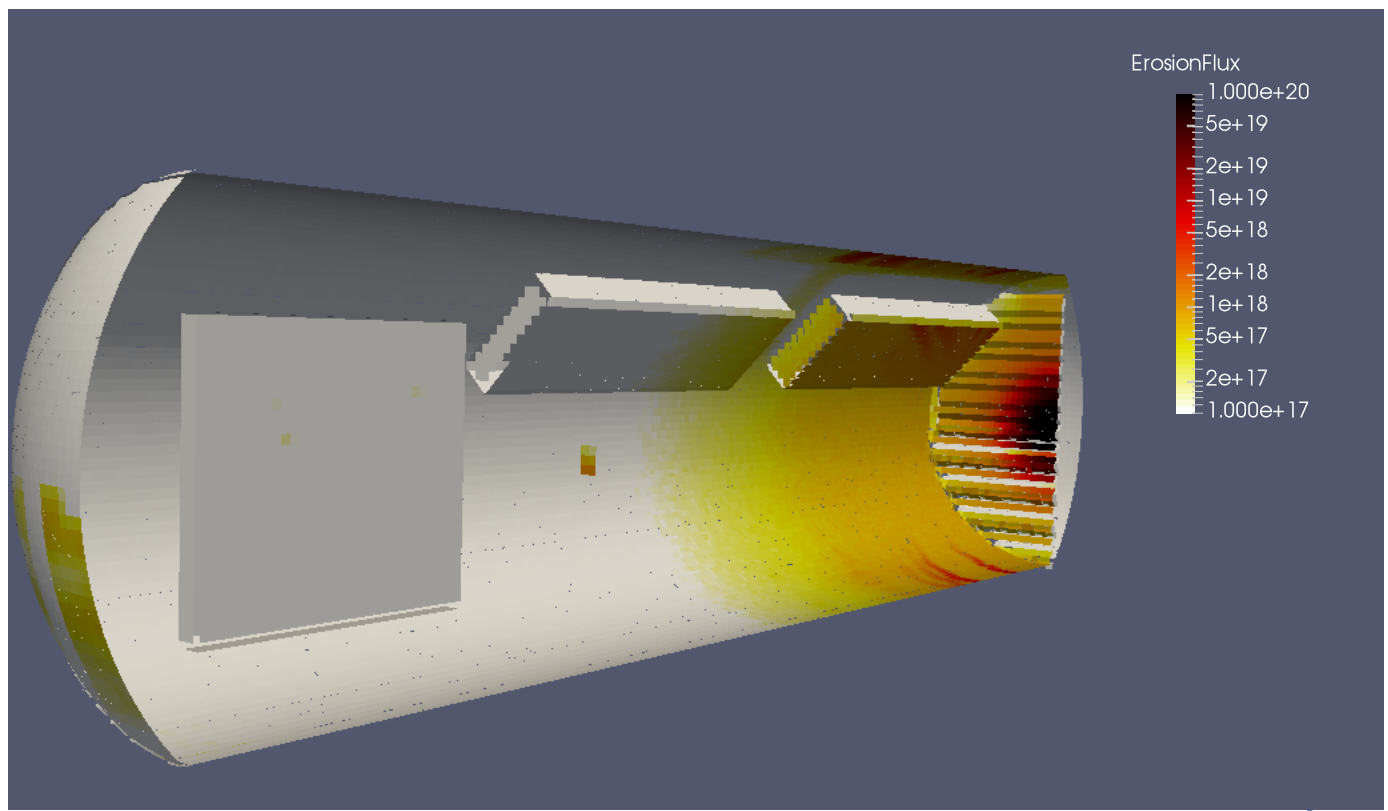

Figure 11. Primary carbon sputtering regions in VF-5 for the $12.5 \mathrm{~kW}, 600 \mathrm{~V}$ case. Units are \#/m $\mathrm{m}^{2}$, and the scale is a log scale.

9

American Institute of Aeronautics and Astronautics 


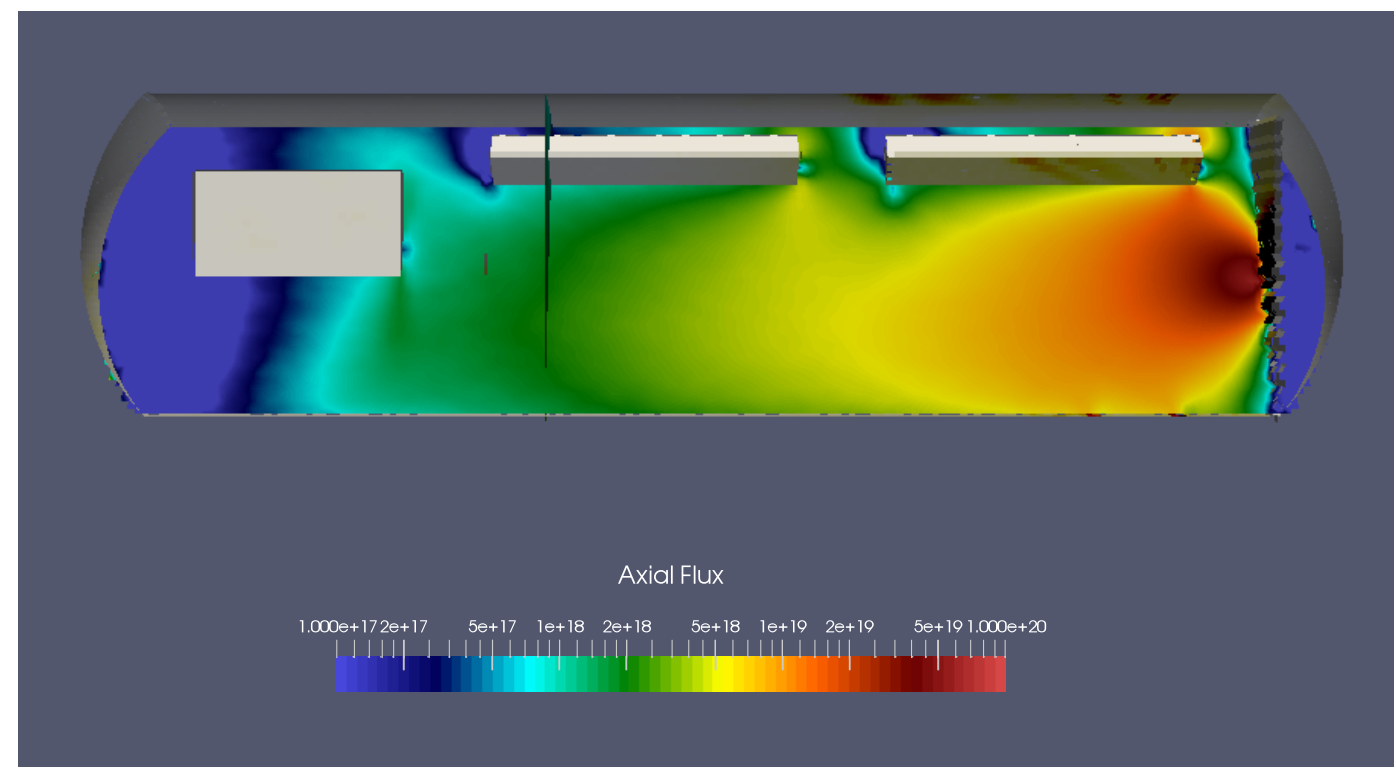

Figure 12. Carbon axial flux through the chamber, shown in cross section to capture flow from the pumping panels. The vertical line to the left of center is the sampling area for axial flux to the thruster. The thruster is located $1.1 \mathrm{~m}$ to the left of this surface.

geometry are still of interest for determing facility effects, and are presented here. HAP calculates the total carbon evolved at the facility surfaces and the flow of this carbon throughout the chamber, taking into consideration the pumping or sticking of the carbon. Possible interactions with the xenon plume are also included in a monte carlo collision sense, with VHS diameters for both particles allowing for random collisions.

The total local production of carbon at the surface for the $600 \mathrm{~V}, 12.5 \mathrm{~kW}$ case is shown in Figure 11. The scale extends over three decades of values, from $10^{17}$ to $10^{20}$ particles $/ \mathrm{m}^{2}$. Primary sputtering occurs at the beam dump and the side walls and pumping surfaces closest to the beam dump. This is the total sputtered particle yield from the surfaces, with the directional distribution then determined by the assumed cosine variation in the number of particles released at each surface. This surface value is calculated simultaneously with the carbon density and flux through the chamber, as shown in Figure 12. . The longitudinal cross section used to show the flow trends is at an angle to the vertical, in order to capture the contributions of the upper cryopump surfaces, which do not extend to the center of the chamber. While the absolute values are, as previously noted, higher than experimental measurements, the highest calculated axial sputter flux occurs toward the end of the chamber, as was found in the analytic model. The overall flow shows that approximately $2 \%$ of the peak sputtered axial flux at the end of the chamber reaches the thruster plane

The distribution of sputtered carbon across the cross section one meter ahead of the thruster is shown in Figure 13. The thruster scaled and location are shown by a white circle for reference. Because the thruster is located $10 \mathrm{~cm}$ below the chamber axis, and the pumping surfaces are primarily at the top of the chamber, some vertical asymmetry is apparent. However, across much of the cross section, and near the thruster, the calculated distribution is relatively uniform. The symmetry of the system drives symmetry about the vertical axis. Although the numerical modeling agrees qualitatively in terms of uniformity near the thruster, the predicted deposition magnitude is far higher than that predicted by the analytic code, and greater than that measured in HERMeS testing, which will be discussed next.

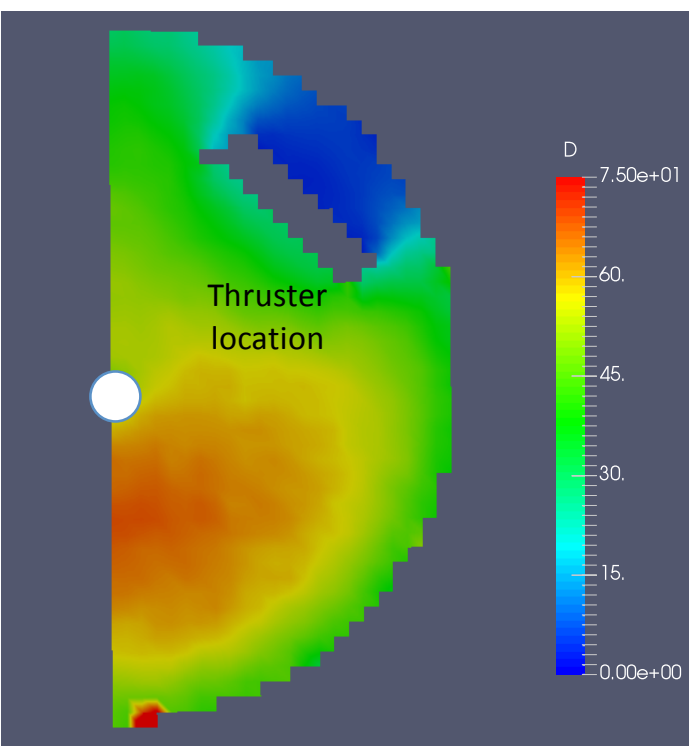

Figure 13. Carbon axial flux at plane $1.1 \mathrm{~m}$ in front of thruster. 


\section{B. Experimental Results}

Some representative data from recent testing are shown in Figure 14. The QCM-3 absolute thickness was corrected for a constant thickness offset which occurred due to a controller reset of the thickness after an unexpected system power outage over the course of testing. Variations in rate over the course of weeks represents a combination of short term operation over a range of operating conditions, extended operation at the wear test condition, and some probing using the facility's probe suite. ${ }^{26}$ Probing was observed to increase instantaneous back sputter rates up to two or three times when the probe is in the peak density and energy regions at the center of the plume, but probing represents a total of one to two hours total out of the entire wear test.

Numerical values for the measured rates at the wear test operating condition are given in Table 1, with the analytically predicted value for $600 \mathrm{~V}$ also listed. The measured deposition rates on either side of the thruster and in the vertical direction are within $10 \%$ of the mean, this is comparable to the measurement accuracy of the QCMs at this early stage in the wear test. The spacing between the two sides of the thruster is one the order of $2 \mathrm{~m}$. The predicted $10 \%$ uniformity of the deposition rate over the chamber radius corresponds to that seen in the experiment. Two values for each QCM are given due to the varying conditions over which the thruster was operated in the initial wear testing. Specifically, the thruster was tested with two pole cover materials, graphite and $\mathrm{Al}_{2} \mathrm{O}_{3}$, to address potential pole wear concerns. ${ }^{25}$ Some variation, close to that observed in the QCM rate resolution, was observed. This variation was comparable to the variation between QCM's for a given condition. Plume measurements for both cases indicated a greater flux of particles at higher energies at high angles from the axis for the graphite plume; the plume differences follow the trend of slightly higher (15\%) deposition for the graphite pole covers. Measured deposition rates are lower than predicted by the analytic model; possible reasons for this will be discussed in the conclusions.

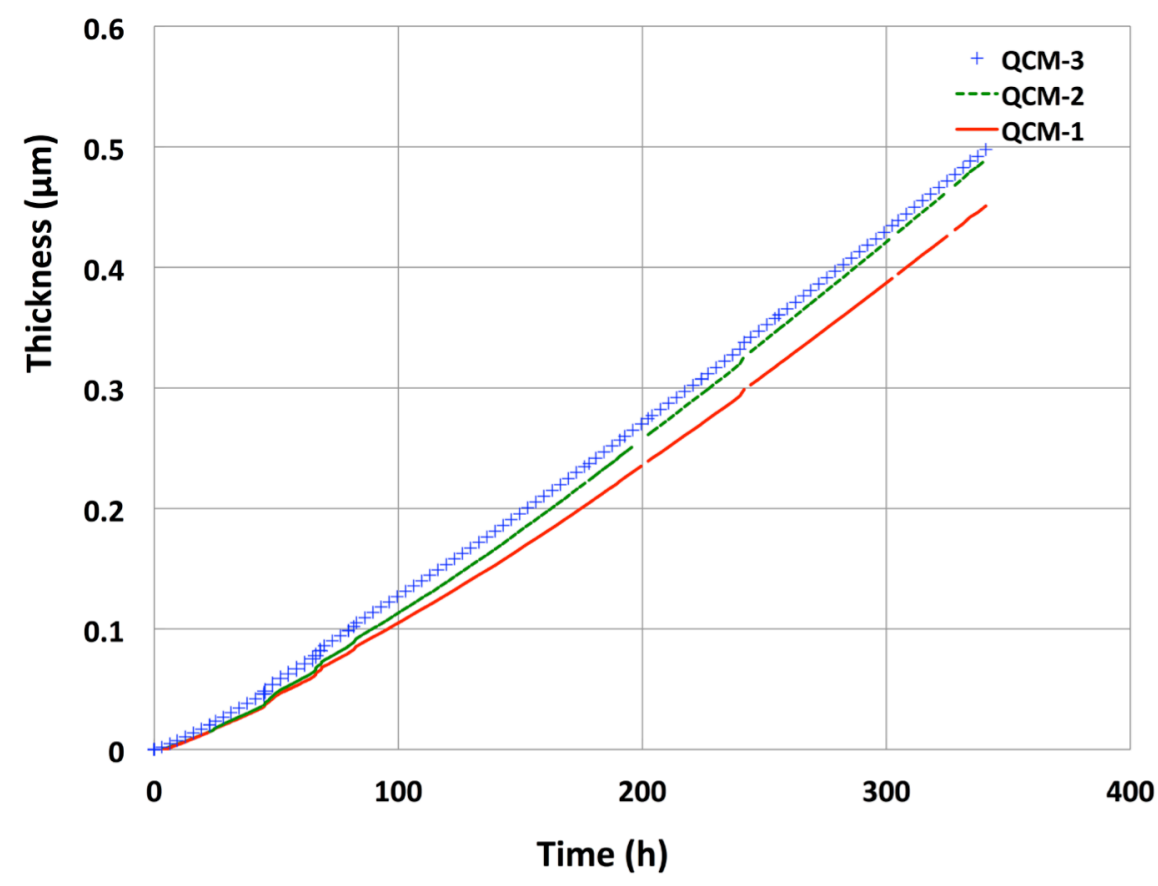

Figure 14. QCM measurements for three locations across thruster, showing the uniformity of the deposition rate. 
Table 1. Representative QCM measurements at $600 \mathrm{~V}, 12.5 \mathrm{~kW}$ during first 400 hours of HERMeS TDU-1 operation.

\begin{tabular}{c|c|c|c|c}
\hline Pole Cover & QCM 1 & QCM 2 & QCM 3 & $\begin{array}{c}\text { Analytic } \\
\text { Prediction }\end{array}$ \\
\hline Graphite & 1.74 & 1.90 & 1.81 & 1.1 \\
$\mathrm{Al}_{2} \mathrm{O}_{3}$ & 1.55 & 1.67 & 1.63 & \\
\hline
\end{tabular}

\section{Conclusion}

In order to better assess the facility requirements and predict the results of life testing in high-power Hall Effect thrusters, the physics of facility back sputter creation and transport in vacuum facilities has been modeled using two different approaches: 1.) a quasi-analytic approach that uses line-of-sight assumptions, but incorporates a detailed Hall thruster plume profile of both current and energy and 2.) a numerical DSMC approach that incorporates both a detailed vacuum facility geometry (NASA Glenn's VF-5) and a Hall thruster plume profile. The predictions have been compared to recent experimental measurements for the same thruster that was modeled. The analytic model has been found to under estimate back sputter rates near the thruster, with a value $60 \%$ to $70 \%$ of the measured rates. The model does reproduce the uniform deposition profile observed in VF-5. The HAP DSMC code is currently over predicting sputter rates, but offers the promise for a more accurate deposition profile due to it's ability to incorporate detailed vacuum chamber facilities.

In terms of predicting trends, the analytic code can be used to assess plume profile impacts; this was done recently with two different plume profiles from probe data to assess the impact of different modes of thruster operaton on back sputter. The preliminary assessment indicated a similar relative change in back sputter rates to what was measured by the QCM's in each mode of operation, although the absolute magnitudes did not match that measured. Some potential refinements to the analyses to better predict the back sputter environment would be to improve modeling of the plume and incorporating the possible effects of charge exchange in the far field. Further testing with the HAP code to identify the source of the excess carbon will continue. The inclusion of a more detailed sputtered particle distribution, similar to that observed in some sputtering experiments, will also be examined for both the analytic and HAP models.

As part of the ongoing experimental effort, the QCM measurements are being augmented with witness samples, including boron nitride samples located adjacent to a QCM. Some of these samples have been examined for structure and composition, and the while results are preliminary, examination of the structure of the deposited film by X-Ray diffraction indicates that it is an amorphous structure. Assessment of the film composition through scanning electron microscopy shows predominantly carbon, with some traces of heavier atoms such as aluminum and silicon. Some of these other materials may have been sputtered from the probe and probe arm during probe sweeps, when the measured deposition rate measured by the QCMs increases.

\section{References}

${ }^{1}$ Herman, D. A., et al., "The Ion Propulsion System for the Asteroid Redirect Robotic Mission," to be presented at $52^{\text {nd }}$ AIAA/SAE/ASEE Joint Propulsion Conference, Salt Lake City, UT, July 24-27, 2016.

${ }^{2}$ Kamhawi, H., et al. (2014). "Overview of the Development of the Solar Electric Propulsion Technology Demonstration Mission 12.5-kW Hall Thruster," AIAA 2014-3898, 50th AIAA/SAE/ASEE Joint Propulsion Conference, Cleveland, OH.

${ }^{3}$ Hofer, R. R., et al. (2015). "Design Methodology and Scaling of the $12.5 \mathrm{~kW}$ HERMeS Hall Thruster for the Solar Electric Propulsion Technology Demonstration Mission." presented at the 62nd JANNAF Propulsion Meeting, Nashville, TN

${ }^{4}$ Mikellides, I., Hofer, R. R., Katz, I., and Goebel, D. M., "Magnetic Shielding of Hall Thrusters at High Discharge Voltages," Journal of Applied Physics, Vol. 116, No. 5, 053302, 2014.

5 Kamhawi, H., Manzella, D. H., Smith, T. B., and Schmidt, G. R. . "High-Power Hall Propulsion Development at NASA Glenn Research Center." IAC-12-C4.4.6, Space Propulsion 2012, Bordeaux, France.

${ }^{6}$ Myers, J., Kamhawi, H., and Yim, J. "HERMeS Thermal Model." 51st AIAA/SAE/ASEE Joint Propulsion Conference, Orlando, FL, July 2015.

${ }^{7}$ Lopez Ortega, A., Mikellides, I., and Katz, I. (2015). "Hall2de Numerical Simulations for the Assessment of Pole Erosion in a Magnetically-Shielded Hall Thruster." 30th International Electric Propulsion Conference, Kobe, Hyogo, Japan. 
${ }^{8}$ Florenz, R. et al., "Electric Propulsion of a Different Class: The Challenges of Testing for MegaWatt Missions," AIAA 2012-3942, 48th AIAA/ASME/SAE/ASEE Joint Propulsion Conference, Atlanta GA, July 30 - August 1, 2012.

${ }^{9}$ Byers, D and J. W. Dankanich, "A Review of Facility Effects on Hall Effect Thrusters," IEPC 2009-076, 31st International Electric Propulsion Conference, Sept. 20-24, 2009, Ann Arbor, MI.

${ }^{10}$ Dankanich, J. W., M W. Swiatek, and J. T. Yim, "A Step Towards Electric Propulsion Testing Standards: Pressure Measurements and Effective Pumping Speeds," AIAA 2012-3737, 48 ${ }^{\text {th }}$ AIAA/SAE/ASEE Joint Propulsion Conference, Atlanta, GA, 2012.

${ }^{11}$ Dankanich, J. W., M. Walker, M. W. Swiatek, and J. T. Yim, "Recommended Practice for Pressure Measurements and Calculation of Effective Pumping Speeds during Electric Propulsion Testing," IEPC 2013-358, 33rd International Electric Propulsion Conference, Washington, D.C., October 6 - 10, 2013.

${ }^{12}$ Frieman, J. D., Walker, J., A., Khayms, V., King, D. Q., Walker, M. L. R., "Electrical Facility Effects on Hall Effect Thruster Cathode Coupling - Performance and Plume Properties," J. of Prop. and Power, Volume 32, Number 1, JanuaryFebruary 2016, pp. 251-264.

${ }^{13}$ Soulas, G., "The Impact of Back sputtered Carbon on the Accelerator Grid Wear Rates of the NEXT and NSTAR Ion Thrusters," IEPC 2013-157, $33^{\text {rd }}$ International Electric Propulsion Conference, Washington, D.C., October 6-10, 2013.

${ }^{14}$ Sovey, J., and M. Mantenieks, "Performance and lifetime assessment of magnetoplasmadynamic arc thruster technology," J. Prop. and Power, 7:71-83, January 1991.

${ }^{15}$ Nakles, M. R. and W. A. Hargus, "Background Pressure Effects on Ion Velocity Distribution Within a Medium-Power Hall Thruster," J. Prop. and Power, Vol. 27, No. 4.

${ }^{16}$ Strange, et al., "Overview of Mission Design for NASA Asteroid Redirect Robotic Mission Concept," IEPC 2013-321, 33 ${ }^{\text {rd }}$ International Electric Propulsion Conference, Washington, D.C., October 6 - 10, 2013.

${ }^{17}$ Hofer, R. R., et al., "Wear test of a magnetically shielded Hall thruster at 3000 seconds specific impulse,” IEPC 2013-033, $33^{\text {rd }}$ International Electric Propulsion Conference, Washington, D.C., October 6 - 10, 2013.

${ }^{18}$ Kolasinski, R. D., J. Polk, D. Goebel, and L. Johnson, "Carbon Sputtering Yield Measurements at Grazing Incidence," 42nd AIAA/ASME/SAE/ASEE Joint Propulsion Conference \& Exhibit, AIAA Paper 2006-4337, Sacramento, California, July 2006.

${ }^{19}$ Yalin, A.P., B. Rubin, S.R. Domingue, Z. Glueckert, and J. D. Williams, "Differential Sputter Yields of Boron Nitride, Quartz, and Kapton Due to Low Energy Xe+ Bombardment," AIAA 2007-5314, 43rd AIAA/ASME/SAE/ASEE Joint Propulsion Conference, Cincinnati, OH, 8-11 July 2007.

${ }^{20}$ Reynolds, T., "Mathematical Representation of Current Density Profiles from Ion Thrusters," 7th AIAA/SAE Propulsion Joint Specialist Conference, AIAA-71-693, Salt Lake City, UT, June 14-18, 1971.

${ }^{21}$ Van Noord, J.L., Soulas, G.C., "A Facility and Ion Thruster Back Sputter Survey for Higher Power Ion Thrusters,” AIAA2005-4067, 41 st AIAA/SAE/ASEE Joint Propulsion Conference, Tucson, AZ, 2005.

${ }^{22}$ Lopez Ortega, A., I. Katz, I. G. Mikellides and D. M. Goebel, "Self-Consistent Model of a High-Power Hall Thruster Plume," in IEEE Transactions on Plasma Science, vol. 43, no. 9, pp. 2875-2886, Sept. 2015.

doi: 10.1109/TPS.2015.2446411

${ }^{23}$ Burt, J. M., E. Josyula, and I. D. Boyd. "Novel Cartesian Implementation of the Direct Simulation Monte Carlo Method", Journal of Thermophysics and Heat Transfer, Vol. 26, No. 2 (2012), pp. 258-270.

${ }^{24}$ Yim J. T., D. A. Herman, and J. M. Burt, "Modeling Analysis for NASA GRC Vacuum Facility 5 Upgrade,” NASA/TM2013-216496, February 2013.

${ }^{25}$ Williams, G. W., et al., "2000-hour Wear-Testing of the HERMeS Thruster," to be presented at 52 ${ }^{\text {nd }}$ AIAA/SAE/ASEE Joint Propulsion Conference, Salt Lake City, UT, July 24-27, 2016.

${ }^{26}$ Kamhawi, H. et al., "Performance and Stability Characterization Tests of NASA's 12.5-kW Hall Effect Rocket with Magnetic Shielding Thruster," to be presented at $52^{\text {nd }}$ AIAA/SAE/ASEE Joint Propulsion Conference, Salt Lake City, UT, July 24-27, 2016. 